\title{
Preliminary Epidemiology of Human Infections with Highly Pathogenic Avian Influenza A(H7N9) Virus, China, 2017
}

\begin{abstract}
Lei Zhou, ${ }^{1}$ Yi Tan, ${ }^{1}$ Min Kang, ${ }^{1}$ Fuqiang Liu, ${ }^{1}$ Ruiqi Ren, ${ }^{1}$ Yali Wang, Tao Chen, Yiping Yang, Chao Li, Jie Wu, Hengjiao Zhang, Dan Li, Carolyn M. Greene, Suizan Zhou,

A. Danielle luliano, Fiona Havers, Daxin Ni, Dayan Wang, Zijian Feng, Timothy M. Uyeki, Qun Li

We compared the characteristics of cases of highly pathogenic avian influenza (HPAl) and low pathogenic avian influenza (LPAI) A(H7N9) virus infections in China. HPAI A(H7N9) case-patients were more likely to have had exposure to sick and dead poultry in rural areas and were hospitalized earlier than were LPAI A(H7N9) case-patients.
\end{abstract}

Since the first human infections with avian influenza A(H7N9) virus were identified in early 2013 (1), mainland China has experienced 5 epidemics of human infections with A(H7N9) virus (2). As of March 31,2017 , a total of 1,336 cases of laboratory-confirmed $\mathrm{A}(\mathrm{H} 7 \mathrm{~N} 9)$ virus infections were detected; case-fatality proportion was $\approx 40 \%$. The fifth epidemic began September 1, 2016, and the number of A(H7N9) virus infection cases has surged since December 2016 (2). Until recently, all human infections were with low pathogenic avian influenza (LPAI) A(H7N9) virus, which causes little or no disease in infected poultry. Risk factors for human infection with LPAI A(H7N9) virus include visiting a live poultry market (LPM) or raising backyard poultry, and mortality is higher among older adults with chronic comorbid conditions $(3,4)$.

On February 18, 2017, the National Health and Family Planning Commission of China reported genetic sequencing results on virus isolates from 2 patients from Guangdong Province who had A(H7N9) virus infection

Author affiliations: Chinese Center for Disease Control and Prevention, Beijing, China (L. Zhou, R. Ren, Y. Wang, T. Chen, C. Li, D. Li, D. Ni, D. Wang, Z. Feng, Q. Li); Guangxi Center for Disease Control and Prevention, Nanning, China (Y. Tan, Y. Yang); Guangdong Center for Disease Control and Prevention, Guangzhou, China (M. Kang, J. Wu); Hunan Center for Disease Control and Prevention, Changsha, China (F. Liu, H. Zhang); Centers for Disease Control and Prevention, Atlanta, Georgia, USA (C.M. Greene, S. Zhou, A.D. Iuliano, F. Havers, T.M. Uyeki)

DOI: https://doi.org/10.3201/eid2308.170640 (initially reported to the Chinese Center for Disease Control and Prevention [China CDC] in January 2017) that were consistent with highly pathogenic avian influenza (HPAI) viruses. Insertions at the hemagglutinin gene cleavage site consistent with HPAI A(H7N9) virus were confirmed by the Chinese National Influenza Center (CNIC) (5). Detection of HPAI A(H7N9) virus in LPMs in Guangdong Province was reported on February 20, 2017 (6). An additional case of HPAI A(H7N9) virus infection was identified in Taiwan in a patient with illness onset in Guangdong Province $(5,7,8)$. To assess whether disease severity in humans has changed with HPAI A(H7N9) compared with LPAI A(H7N9) virus infection, we described the epidemiologic characteristics of cases of HPAI and LPAI A(H7N9) virus infections identified during the current fifth epidemic in mainland China.

\section{The Study}

Detection, reporting, and confirmation of HPAI A(H7N9) virus infection was the same as for LPAI $\mathrm{A}(\mathrm{H} 7 \mathrm{~N} 9)$ and HPAI A(H5N1) virus infections, as previously described $(3,9,10)$. Since the first case of HPAI A(H7N9) virus infection was identified in 2017, genetic analyses are performed at provincial China CDC laboratories or at CNIC on respiratory specimens collected from all case-patients identified with $\mathrm{A}(\mathrm{H} 7 \mathrm{~N} 9)$ virus infection to distinguish between HPAI and LPAI A(H7N9) viruses. Field investigations and data collection protocols for HPAI A(H7N9) cases were the same as for LPAI A(H7N9) cases (3).

We extracted information from field investigation reports and the notifiable infectious surveillance system to describe the demographic, clinical, and epidemiologic characteristics of HPAI A(H7N9) case-patients. We used descriptive statistics to compare HPAI A(H7N9) cases with all LPAI A(H7N9) cases reported throughout mainland China and with LPAI A(H7N9) cases identified in the same provinces as HPAI A(H7N9) cases during the fifth epidemic reported as of March 31, 2017. Collection and analyses of data from human infections with $\mathrm{A}(\mathrm{H} 7 \mathrm{~N} 9)$ virus were determined to be part of an ongoing public health investigation of emerging outbreaks and thus were exempt from institutional review board assessment in China (3).

${ }^{1}$ These authors contributed equally to this article. 


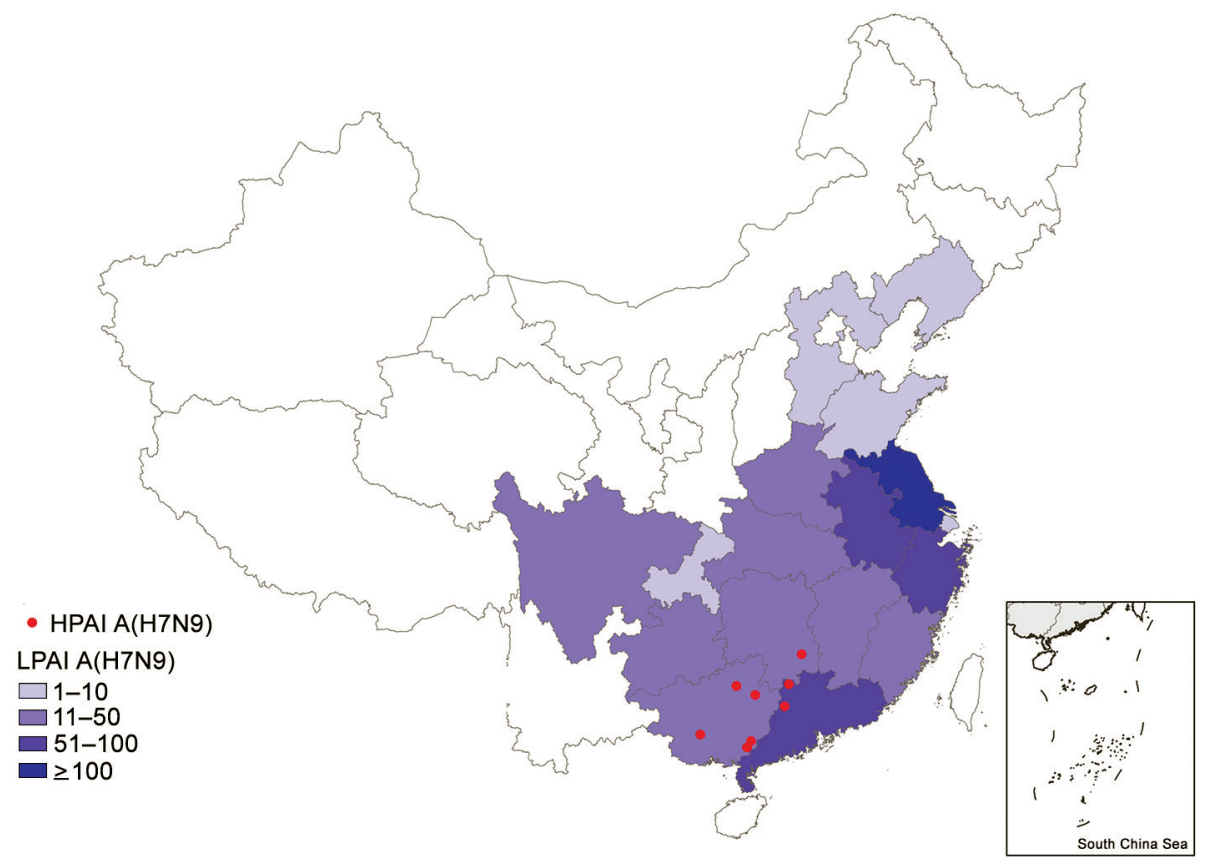

Figure 1. Geographic distribution of human cases of infection with HPAI A(H7N9) virus, China, September 1 , 2016-March 31, 2017. The red circles indicate the counties with HPAI A(H7N9) virus infections within Guangxi, Guangdong, and Hunan Provinces during the fifth epidemic. Shading indicates the total numbers of LPAI A(H7N9) virus infections by province during the fifth epidemic. HPAI, highly pathogenic avian influenza; LPAI, low pathogenic avian influenza.
Eight cases of HPAI A(H7N9) virus infection were identified from 3 provinces in southern China (Figure 1). The first 2 case-patients had illness onset on December 30, 2016, and January 5, 2017, in Guangdong Province. Additional case-patients were identified in Hunan and Guangxi Provinces with illness onset during February 2017 (Figure 2 ). Of the 8 total case-patients, the median age was 57 years (range 28-71 years), and 4 (50\%) were male. Most (75\%) case-patients lived in rural areas, as defined previously (4), and all were exposed to poultry within 10 days of illness onset. Five case-patients had exposure to backyard poultry, including 4 exposed to sick or dead poultry; 2 had household exposure to poultry purchased from LPMs, including 1 with poultry that were sick and died in the home; and 1 was a poultry worker who sold and slaughtered poultry at an LPM. One cluster of HPAI A(H7N9) cases was identified in 2 adult sisters; 1 sister had household exposure to sick and dead poultry, and the other sister had exposures to sick and dead poultry at her sister's house, to poultry brought inside her home from her sister's house, and to her ill sister while that sister was hospitalized.

All 8 HPAI A(H7N9) case-patients were admitted to hospital a median of 2.5 days (range $0-5$ days) after illness onset. All 8 case-patients received oseltamivir treatment a median of 4 days (range 1-8 days) after illness onset; 7 were admitted to an intensive-care unit, and 6 were placed on mechanical ventilation for a median of 5.5 days (range 4-7 days) after illness onset. Four case-patients died a median of 6.5 days (range 5-44 days) after illness onset, and 4 recovered and were discharged home after a median of 29 days (range 21-52 days) (Table).
Compared with all LPAI A(H7N9) case-patients reported during the fifth epidemic, HPAI A(H7N9) case-patients were significantly more likely to live in rural areas $(88 \%$ vs. $47 \% ; p=0.031)$, have exposure to sick or dead poultry ( $50 \%$ vs. $16 \%$; $p=0.037)$, and be hospitalized earlier (median 2.5 vs. 5 days; $p=0.032$ ) (Table). No significant differences were observed in median age, sex, prevalence of underlying chronic medical conditions, median time from illness onset to starting antiviral treatment, or proportion of patients who received oseltamivir treatment, intensive-care unit admission, or mechanical ventilation (Table). Although the median time from illness onset to death ( 6.5 vs. 13 days) was shorter and the overall case-fatality proportion $(50 \%$ vs. $37 \%$ ) was higher for HPAI A(H7N9) case-patients than for LPAI A(H7N9) case-patients, these differences were not statistically significant (Table). When the analysis was restricted to the 3 provinces with HPAI A(H7N9) cases identified during the fifth epidemic, the only significant difference was a shorter median time from illness onset to death for HPAI A(H7N9) case-patients compared with LPAI A(H7N9) case-patients in Guangxi Province (5 vs. 17 days; $\mathrm{p}=0.0192$ ).

\section{Conclusions}

Our preliminary findings indicate that HPAI A(H7N9) virus infection was associated with exposure to sick and dead backyard poultry in rural areas. In the ongoing fifth epidemic in mainland China, HPAI A(H7N9) case-patients were hospitalized earlier than LPAI A(H7N9) case-patients but otherwise had similar epidemiologic characteristics and disease severity. 


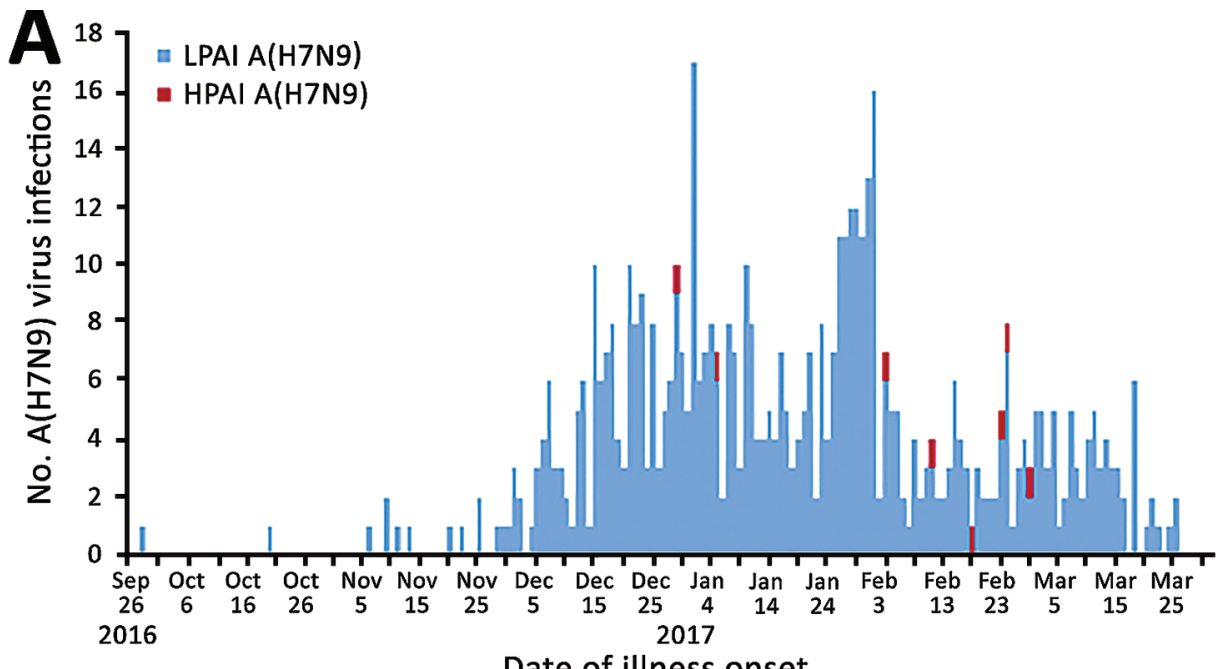

B

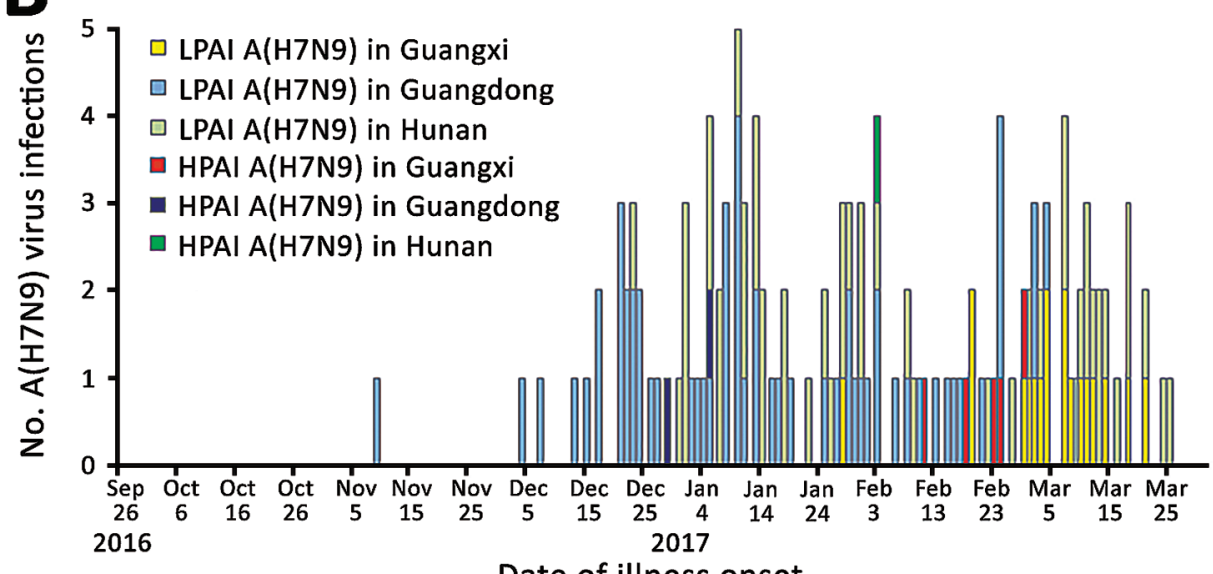

Figure 2. Human infections with HPAI or LPAI A(H7N9) viruses, by illness onset date, China, September 1, 2016-March 31, 2017. A) Dates of illness onset for the 8 HPAl A(H7N9) cases compared with those for all LPAI A(H7N9) cases. B) Dates of illness onset for the 8 HPAI A(H7N9) cases compared with those for LPAI A(H7N9) cases in 3 provinces (Guangxi, Guangdong, and Hunan).
The small number of HPAI A(H7N9) cases limited our statistical power to detect differences in epidemiologic characteristics and disease severity between HPAI and LPAI A(H7N9) case-patients. Data were not available for all variables analyzed, including outcomes for some LPAI A(H7N9) case-patients who remained hospitalized. Our findings might suggest more rapid progression and greater disease severity for HPAI A(H7N9) case-patients, because mortality was higher and the intervals from illness onset to diagnosis and to death were shorter compared with LPAI A(H7N9) case-patients; however, these differences were not significant.

Because $\mathrm{A}(\mathrm{H} 7 \mathrm{~N} 9)$ virus circulation among poultry is ongoing in mainland China, extensive efforts are needed to prevent and control the spread of LPAI and HPAI A(H7N9) viruses among poultry, including in rural areas. Avoidance of sick or dead poultry that might be infected with HPAI $\mathrm{A}(\mathrm{H} 7 \mathrm{~N} 9)$ virus can reduce transmission of HPAI A(H7N9) virus to humans. Enhanced surveillance of HPAI and LPAI $\mathrm{A}(\mathrm{H} 7 \mathrm{~N} 9)$ viruses in poultry and humans, timely virus characterization, and ongoing assessments of the epidemiology of human infections with $\mathrm{A}(\mathrm{H} 7 \mathrm{~N} 9)$ viruses are critical to guide prevention and control efforts and to provide information on the risk of these novel influenza A viruses to public health.

\section{Acknowledgments}

We thank staff members in the local and provincial China CDC sites for providing assistance with data collection. We also thank Yuelong Shu and colleagues at CNIC for their contributions to laboratory testing and analyses to confirm HPAI A(H7N9) virus infections.

This work was supported by the Ministry of Science and Technology of China, Emergency Technology Research Issue on Prevention and Control for Human Infection with A(H7N9) Avian Influenza Virus (grant no. KJYJ-2013-01-02), the China-US Collaborative Program on Emerging and Re-emerging Infectious Disease, and National Mega-Projects for Infectious Diseases (grant no. 2014ZX10004002-002-004). 
Table. Selected characteristics of case-patients with HPAI and LPAI A(H7N9) virus infections, mainland China, September 1, 2016March 31, 2017*

\begin{tabular}{|c|c|c|c|}
\hline \multirow[b]{2}{*}{ Characteristics } & \multicolumn{2}{|c|}{ Infection type } & \multirow[b]{2}{*}{$p$ value } \\
\hline & HPAI, $n=8$ & LPAI, $\mathrm{n}=553$ & \\
\hline Median age (range), y & $56.5(28-71)$ & $57(3-91)$ & $0.632 \dagger$ \\
\hline \multicolumn{4}{|l|}{ Age group, y } \\
\hline $0-14$ & 0 & $5 / 553(1)$ & NA \\
\hline $15-59$ & $5(63)$ & $313 / 553(57)$ & - \\
\hline$\geq 60$ & $3(38)$ & $235 / 553(42)$ & - \\
\hline \multicolumn{4}{|l|}{ Sex } \\
\hline M & $4(50)$ & $400 / 553(72)$ & 0.317 \\
\hline $\mathrm{F}$ & $4(50)$ & $153 / 553(28)$ & - \\
\hline \multicolumn{4}{|l|}{ Residence areał } \\
\hline Urban & $1(13)$ & $193 / 364(53)$ & $0.031 \S$ \\
\hline Rural & $7(88)$ & $171 / 364(47)$ & - \\
\hline Having $\geq 1$ underlying medical conditions $\mathbb{T}$ & $5(63)$ & $234 / 432(54)$ & $0.733 \#$ \\
\hline \multicolumn{4}{|l|}{ Poultry exposure within $10 \mathrm{~d}$ of illness onset } \\
\hline Any exposure to poultry & $8(100)$ & $442 / 500(90)$ & $1.000 \S$ \\
\hline Visited live poultry market & $3(38)$ & $324 / 442(73)$ & NA \\
\hline Exposure to backyard poultry & $4(50)$ & $98 / 442(22)$ & NA \\
\hline Occupational exposure to poultry & $1(13)$ & $20 / 442(5)$ & NA \\
\hline Exposure to sick or dead poultry & $4(50)$ & $43 / 268(16)$ & $0.037 \#$ \\
\hline \multicolumn{4}{|l|}{ Clinical management } \\
\hline Hospitalization & $8(100)$ & $478 / 480(99)$ & NA \\
\hline Antiviral treatment & $8(100)$ & $392 / 404(97)$ & NA \\
\hline ICU & $7(88)$ & $323 / 403(80)$ & 1.000 \\
\hline Mechanical ventilation & $6(75)$ & $221 / 386(57)$ & 0.476 \\
\hline \multicolumn{4}{|l|}{ Timeline of clinical management (median), $\mathrm{d} \dagger$} \\
\hline Illness onset to first medical service seeking & $0.5(0-5)$ & $2(0-34)$ & 0.096 \\
\hline Illness onset to hospitalization & $2.5(0-5)$ & $5(0-35)$ & 0.032 \\
\hline Illness onset to antiviral treatment & $4(1-8)$ & $6(0-29)$ & 0.168 \\
\hline Illness onset to diagnosis & $6.5(4-9)$ & $8(0-31)$ & 0.241 \\
\hline IIIness onset to death & $6.5(5-44)$ & $13(2-62)$ & 0.180 \\
\hline \multicolumn{4}{|l|}{ Outcome } \\
\hline Death & $4(50)$ & $203 / 376(54)$ & 1.000 \\
\hline Recovered and discharged & $4(50)$ & $173 / 376(46)$ & - \\
\hline \multicolumn{4}{|c|}{$\begin{array}{l}\text { "Values are no. (\%) unless otherwise indicated. The } \chi^{2} \text { test was used to compare the variables between HPAI and LPAI groups. Data were missing for } \\
\text { some variables, and data on final outcomes were missing for case-patients with LPAI A(H7N9) virus infection who remained hospitalized as of March } 31 \text {, } \\
2017 \text {. We were not able to perform the statistical analyses to assess differences for some variables because the number of cells with expected frequency } \\
\text { of }<5 \text { was }>20 \% \text { and some cells had expected frequency of }<1 \text {. HPAl, highly pathogenic avian influenza; ICU, intensive-care unit; LPAI, low pathogenic } \\
\text { avian influenza; NA, not available. } \\
\text { †The z-test was used to compare median age and median days of the timeline of clinical management between HPAI and LPAI groups. } \\
\text { fUrban was defined as cities, towns, and suburbs; rural was defined as villages and countryside (3). } \\
\text { §Residence area and "any exposure to poultry" were compared between HPAI and LPAI groups by using the Fisher exact test. } \\
\text { TThree HPAl case-patients had chronic cardiovascular disease, and } 2 \text { HPAI case-patients had chronic metabolic disease. } \\
\text { \#"Having } \geq 1 \text { underlying medical conditions" and "exposure to sick or dead poultry" were compared between HPAI and LPAI groups by using the } \chi^{2} \text { test for } \\
\text { continuous correction. }\end{array}$} \\
\hline
\end{tabular}

L.Z., T.M.U., and Q.L. conceived, designed, and supervised the study; A.D.I. and F.H. helped with study conception and design; Y.T., M.K., F.Q.L., R.Q.R., Y.L.W., Y.P.Y., C.L., J.W., H.J.Z., and D.L. assisted in data collection; T.C. and D.Y.W. assisted in specimens collection and laboratory testing; L.Z. and R.Q.R. analyzed the data; L.Z. and T.M.U. finalized the analysis; L.Z. wrote the draft of the manuscript; T.M.U., C.M.G., S.Z.Z., F.H., A.D.I., D.X.N., Z.J.F., and Q.L. helped interpret the findings; T.M.U., C.M.G., S.Z.Z., F.H., and A.D.I. commented on and helped revise drafts of the manuscript. L.Z. is guarantor.

Dr. Zhou is the Deputy Chief of the Branch for Emerging Infectious Diseases, Public Health Emergency Center, China CDC. Her research interests are prevention and control of emerging infectious diseases as well as pandemic influenza preparedness and response.

\section{References}

1. Gao R, Cao B, Hu Y, Feng Z, Wang D, Hu W, et al. Human infection with a novel avian-origin influenza $\mathrm{A}$ (H7N9) virus. N Engl J Med. 2013;368:1888-97. http://dx.doi.org/10.1056/ NEJMoa1304459

2. Iuliano AD, Jang Y, Jones J, Davis CT, Wentworth DE, Uyeki TM, et al. Increase in human infections with avian influenza A(H7N9) virus during the fifth epidemic — China, October 2016-February 2017. MMWR Morb Mortal Wkly Rep. 2017;66:254-5. http://dx.doi.org/10.15585/mmwr.mm6609e2

3. Li Q, Zhou L, Zhou M, Chen Z, Li F, Wu H, et al. Epidemiology of human infections with avian influenza $\mathrm{A}(\mathrm{H} 7 \mathrm{~N} 9)$ virus in China. N Engl J Med. 2014;370:520-32. http://dx.doi.org/10.1056/ NEJMoa1304617

4. Zhou L, Ren R, Ou J, Kang M, Wang X, Havers F, et al. Risk Factors for influenza A(H7N9) disease in China, a matched case control study, October 2014 to April 2015. Open Forum Infect Dis. 2016;3:ofw182. http://dx.doi.org/10.1093/ofid/ofw182

5. World Health Organization. Human infection with avian influenza A(H7N9) virus - China. Disease outbreak news, 27 February 2017 
[cited 2017 May 16]. http://www.who.int/csr/don/27-february2017-ah7n9-china/en

6. World Organisation for Animal Health (OIE). OIE report of HPAI H7N9 virus infection in poultry, Guangdong Province, China, February 20, 2017 [cited 2017 May 16]. http://www.oie.int/ wahis_2/temp/reports/en_imm_0000022933_20170221_163854.pdf

7. World Health Organization. Human infection with avian influenza A(H7N9) virus - China. Disease outbreak news, 22 February 2017 [cited 2017 May 16]. http://www.who.int/csr/don/22-february2017-ah7n9-china/en

8. Yang JR, Liu MT. Human infection caused by an avian influenza A (H7N9) virus with a polybasic cleavage site in Taiwan, 2017. J Formos Med Assoc. 2017;116:210-2. http://dx.doi.org/10.1016/ j.jfma.2017.02.011
9. Xu C, Havers F, Wang L, Chen T, Shi J, Wang D, et al. Monitoring avian influenza A(H7N9) virus through national influenza-like illness surveillance, China. Emerg Infect Dis. 2013;19:1289-92. http://dx.doi.org/10.3201/ eid1907.130662

10. Yu H, Gao Z, Feng Z, Shu Y, Xiang N, Zhou L, et al. Clinical characteristics of 26 human cases of highly pathogenic avian influenza A (H5N1) virus infection in China. PLoS One. 2008;3:e2985. http://dx.doi.org/10.1371/journal.pone.0002985

Address for correspondence: Qun Li, Public Health Emergency Center, Chinese Center for Disease Control and Prevention, Beijing, 102206, China; email: liqun@chinacdc.cn

\section{May 2011: Vectorborne Infections}

- Intravenous Artesunate for Severe Malaria in Travelers, Europe

- Lessons Learned about Pneumonic Plague Diagnosis, Democratic Republic of the Congo

- Evolution of New Genotype of West Nile Virus in North America

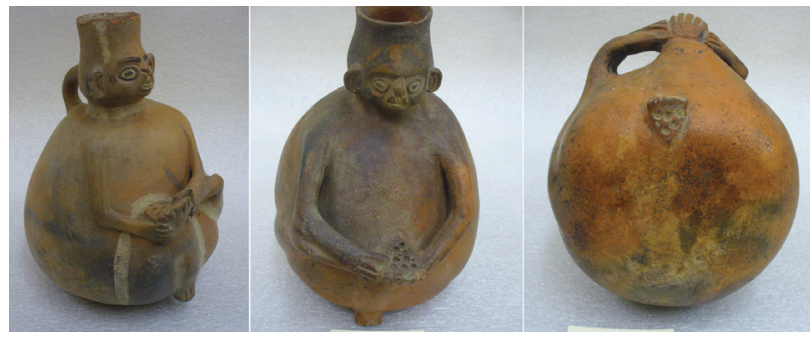

- Transstadial Transmission of Francisella tularensis holarctica in Mosquitoes, Sweden

- Molecular Epidemiology of Oropouche Virus, Brazil

- Severe Imported Plasmodium falciparum Malaria, France, 1996-2003

- Plasmodium knowlesi Malaria in Children, Malaysia

- Travel-related Dengue Virus Infection, the Netherlands, 2006-2007

- Experimental Infection of Amblyomma aureolatum Ticks with Rickettsia rickettsii

- Genotypic Profile of Streptococcus suis Serotype 2 and Clinical Features of Infection in Humans, Thailand

- Babesiosis in Lower Hudson Valley, New York, USA

- Experimental Oral Transmission of Atypical Scrapie to Sheep
- Evidence of Tungiasis in Pre-Hispanic America

- Human Intraocular Filariasis Caused by Dirofilaria sp. Nematode, Brazil

- Human Intraocular Filariasis Caused by Pelecitus sp. Nematode, Brazil

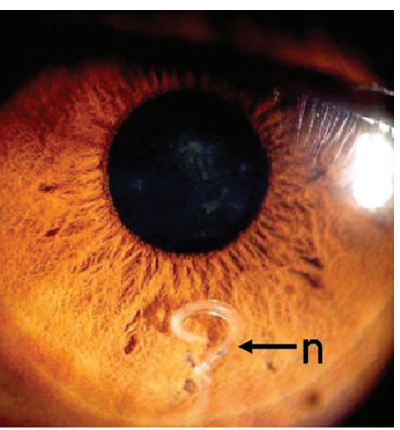

- Linguatula serrata Tongue Worm in Human Eye, Austria

- Rickettsia rickettsii Transmission by a Lone Star Tick, North Carolina

- Tick-Borne Encephalitis Virus, Kyrgyzstan

- Probable Non-Vector-borne Transmission of Zika Virus, Colorado, USA

- Tick-Borne Relapsing Fever Borreliosis, Rural Senegal

- Novel Bluetongue Virus Serotype, Kuwait

- Spotted Fever Group Rickettsiae in Ticks, Germany

- Bartonella spp. in Feral Pigs, Southeastern United States
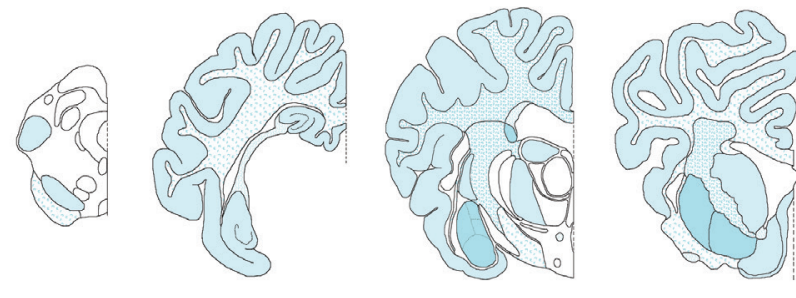

$\sqrt{n}$ 